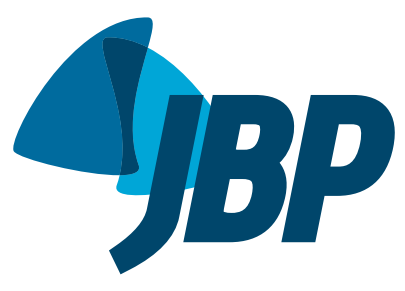

\title{
Is a low level of education a limiting factor for asthma control in a population with access to pulmonologists and to treatment?
}

\author{
Cassia Caroline Emilio',a, Cintia Fernanda Bertagni Mingotti1,b, \\ Paula Regina Fiorin ${ }^{1, c}$, Leydiane Araujo Lima ${ }^{1, d}$, Raisa Lemos Muniz ${ }^{1, e}$, \\ Luis Henrique Bigotto ${ }^{1, f}$, Evaldo Marchi ${ }^{2, g}$, Eduardo Vieira Ponte ${ }^{1, h}$
}

1. Departamento de Clínica Médica Faculdade de Medicina de Jundiaí, Jundiaí (SP) Brasil.

2. Departamento de Cirurgia, Faculdade de Medicina de Jundiaí, Jundiaí (SP) Brasil.

a. (D) http://orcid.org/0000-0001-9414-1389

b. (ID http://orcid.org/0000-0002-4759-9562

c. iD http://orcid.org/0000-0002-6263-9833

d. (D) http://orcid.org/0000-0001-5471-7523

e. (ID http://orcid.org/0000-0002-6819-7108

f. (iD http://orcid.org/0000-0003-4647-4183

g. (iD http://orcid.org/0000-0003-2131-5514

h. (D) http://orcid.org/0000-0003-4868-0124

Submitted: 19 February 2018.

Accepted: 8 June 2018.

Study carried out in the Departamento de Clínica Médica, Faculdade de Medicina de Jundiaí, Jundiá (SP) Brasil.

\begin{abstract}
Objective: To determine whether a low level of education is a risk factor for uncontrolled asthma in a population of patients who have access to pulmonologists and to treatment. Methods: This was a cross-sectional study involving outpatients $>10$ years of age diagnosed with asthma who were followed by a pulmonologist for at least 3 months in the city of Jundiai, located in the state of São Paulo, Brazil. The patients completed a questionnaire specifically designed for this study, the 6-item Asthma Control Questionnaire (to assess the control of asthma symptoms), and a questionnaire designed to assess treatment adherence. Patients underwent spirometry, and patient inhaler technique was assessed. Results: 358 patients were enrolled in the study. Level of education was not considered a risk factor for uncontrolled asthma symptoms $(O R=$ 0.99; 95\% Cl: 0.94-1.05), spirometry findings consistent with obstructive lung disease $(O R=1.00 ; 95 \% \mathrm{Cl}: 0.99-1.01)$, uncontrolled asthma $(\mathrm{OR}=1.03 ; 95 \% \mathrm{Cl}: 0.95-1.10)$, or the need for moderate/high doses of inhaled medication $(\mathrm{OR}=0.99 ; 95 \% \mathrm{Cl}$ : $0.94-$ 1.06). The number of years of schooling was similar between the patients in whom treatment adherence was good and those in whom it was poor $(p=0.08)$, as well as between those who demonstrated proper inhaler technique and those who did not ( $p$ $=0.41$ ). Conclusions: Among asthma patients with access to pulmonologists and to treatment, a low level of education does not appear to be a limiting factor for adequate asthma control
\end{abstract}

Keywords: Asthma; Educational status; Spirometry; Treatment adherence and compliance.

\section{INTRODUCTION}

Education affects various aspects of life, including health. In adults with a clinical diagnosis of asthma, a higher level of education is associated with greater knowledge about the disease and greater skill in the use of asthma inhalers, ${ }^{(1)}$ which could facilitate the control of respiratory symptoms. Therefore, it is possible that patients with lower levels of education need more attention from the physician in order to achieve adequate asthma control.

Previous studies have shown that patients with asthma who have lower levels of education also have more respiratory symptoms. ${ }^{(2-4)}$ However, such patients often lack access to physicians, to treatment, or to both. ${ }^{(5)}$ Therefore, in those studies, the higher frequency of respiratory symptoms identified in individuals with low levels of education may have been a consequence of a lack of access to physicians or to treatment, rather than of the level of education per se. It is important to gain a better understanding of the relationship between level of education and asthma control in order to identify the characteristics of patients who are susceptible to uncontrolled asthma, especially in the current landscape. Although some advances have been made, ${ }^{(6,7)}$ most patients with asthma still have not achieved adequate control of their symptoms. ${ }^{(8)}$

The hypothesis of the present study was that a low level of education would not be a limiting factor for the adequate control of asthma in a population of patients who have access to pulmonologists and to treatment, and the main objective was to test that hypothesis. A secondary objective was to assess whether level of education would be associated with variables that contribute to asthma control, such as treatment adherence and correct inhaler technique.

\section{METHODS}

\section{Study population}

We screened consecutive patients at the municipal outpatient pulmonology clinics in the city of Jundiai, located 
in the state of São Paulo, Brazil, and at the outpatient pulmonology clinics of the largest private hospital in the same city. All of the patients had access to a pulmonologist and to free asthma therapy, with inhaled corticosteroids, as well as with long- and short-acting $\beta_{2}$ agonists. The medication is provided via one of two federal programs-the Special Medications Program and the Popular Pharmacy Program-or by pharmacies of the primary health care clinics operated by the city of Jundiai. All of the patients included in the study were screened between August and December of 2017.

\section{Inclusion and exclusion criteria}

The inclusion criteria were being $>10$ years of age, having been diagnosed with asthma, and having therefore been followed by a pulmonologist for at least three months. Pregnant women were excluded.

The following tools were used for the diagnosis of asthma: clinical assessment by a pulmonologist, spirometry, and chest X-ray. For diagnostic purposes, the physician considered reports of typical asthma symptoms, such as episodes of wheezing, coughing, or dyspnea lasting more than six months, and improvement of these symptoms with the use of a bronchodilator or inhaled corticosteroids. The physicians had access to the patients and to their medical records. Spirometry results were categorized as normal or indicative of obstructive lung disease. All patients underwent chest X-ray to exclude those with findings that were inconsistent with the diagnosis of asthma, as per the physician's discretion. HRCT was requested for all patients presenting with uncontrolled symptoms or spirometry findings consistent with obstructive lung disease despite the use of a high dose of inhaled medication ( $>800 \mu \mathrm{g} /$ day of budesonide or equivalent combined with a long-acting $\beta_{2}$ agonist). Patients in whom the HRCT findings were inconsistent with a diagnosis of asthma were excluded from the study.

\section{Study procedure}

All patients completed a questionnaire designed specifically for the study, the 6-item Asthma Control Questionnaire (ACQ-6), ${ }^{(9)}$ and the questionnaire developed by Morisky et al.(10) Patients underwent spirometry, were asked about their educational background, and were evaluated in terms of their inhaler technique.

The first questionnaire, which was prepared specifically for the study by our research team, was designed to collect clinical and demographic data. The ACQ-6 questionnaire, which has been translated to Portuguese and validated for use in Brazil, ${ }^{(9)}$ was used in order to measure the intensity of asthma symptoms. Lower scores on the ACQ-6 indicate fewer asthma symptoms. We used a cut-off point of 1.5 to distinguish between controlled and uncontrolled symptoms. The Morisky et al. questionnaire, ${ }^{(10)}$ which was used in order to estimate treatment adherence, contains four questions that assess patient perceptions of their own treatment adherence. The total score ranges from 0 (good adherence) to 4 (poor adherence). Scores $\geq 2$ were considered indicative of poor treatment adherence.

Patient inhaler technique was evaluated in terms of the number of errors made with the inhaler devices in use during the study period. Pulmonologists observed patients while they used the devices and classified them into two different groups, depending on whether or not there were any errors that affected the effectiveness of the inhaled medication. The results were recorded as the presence or absence of errors. The patients were also asked about their educational background, and the number of years of schooling was recorded. Kindergarten or preschool years were not counted. Patients with $\geq 10$ years of schooling were classified as having a high level of education.

Patients underwent pulmonary function tests with a Koko spirometer (PDS Instrumentation Inc., Louisville, CO, USA). The recommendations of the American Thoracic Society for the test were followed. The spirometer software was updated with reference values for the Brazilian population. Those values were used in order to calculate $\mathrm{FEV}_{1}$ and FVC, both as a percentage of the predicted value.

\section{Statistical analysis}

The primary objective of the study was to assess whether a low level of education is a risk factor for uncontrolled asthma. To that end, binary univariate and multivariate logistic regression analyses were conducted. In those analyses, level of education was inserted as a continuous variable (years of schooling), and asthma control was inserted as a dichotomous variable (controlled or uncontrolled asthma). Uncontrolled asthma was defined as an ACQ-6 score $>1.5$, with or without spirometry findings indicative of obstructive lung disease. Obstructive lung disease was defined as a post-bronchodilator $\mathrm{FEV}_{1} / \mathrm{FVC}$ ratio below the lower limit of normality and an $\mathrm{FEV}_{1}<80 \%$ of the predicted value. ${ }^{(11)}$ We used the backward likelihood ratio method to input data into the model and the Hosmer-Lemeshow test to check the goodness of fit of the model. To identify collinearity, we used the tolerance test and calculated the variance inflation factor.

The secondary objective of the study was to assess whether patient level of education was associated with treatment adherence and correct inhaler technique. As in the previous analysis, level of education was assessed as a continuous variable. Treatment adherence and inhaler technique were assessed as dichotomous variables-good or poor adherence and presence or absence of errors, respectively. In addition, we compared the patients with $\geq 10$ years of schooling and those with $<10$ years of schooling in terms of the clinical and demographic characteristics. We used the Mann-Whitney test to compare continuous and ordinal variables, whereas we used the chi-square test to compare dichotomous variables. All analyses were conducted with the Statistical Package for the Social Sciences, version 13 (SPSS Inc., Chicago, IL, USA). 


\section{Ethical aspects}

The study was approved by the Research Ethics Committee of the Jundiaí School of Medicine (Protocol No. 70427317.8.0000.5412). Written informed consent was obtained from the participating patients or from their parents or legal guardians.

\section{RESULTS}

Table 1 describes the clinical and demographic characteristics of the 358 patients included in the study. The majority of the patients were female. The median age was 49 years, and the median number of years of schooling was 7. The proportion of patients using moderate/high doses of inhaled medication $(\geq 800$ $\mu \mathrm{g} /$ day of budesonide or equivalent + a long-acting $\beta_{2}$ agonist) and of patients with uncontrolled asthma symptoms (ACQ-6 score > 1.5) was $55 \%$ and $32 \%$, respectively. The spirometry findings were consistent with obstructive lung disease in 68 patients (19\%). Table 1 also compares the characteristics of the patients, by level of education. In comparison with the patients with a higher level of education, those with a lower level of education were older, had a greater number of comorbidities, were more frequently exposed to rural environments, were more frequently vaccinated against influenza, and more often used moderate/ high doses of inhaled asthma medications. The two groups were similar in terms of the ACQ- 6 scores and the proportion of patients in whom the spirometry findings were consistent with obstructive lung disease. Treatment adherence was slightly better among the patients with a lower level of education, although the difference was not statistically significant. There was no difference between the two groups regarding the frequency of errors in inhaler use.

Table 2 shows the results of the binary logistic regression analysis adjusted for age, average monthly family income per household member, place of assessment (public or private outpatient clinic), and history of exposure to rural environments. The level of education, analyzed here as a continuous variable (years of schooling), was not found to be a risk factor for any of the indicators of severity: uncontrolled asthma symptoms, as determined by the ACQ-6 score $(\mathrm{OR}=0.99,95 \% \mathrm{CI}$ : 0.94-1.05); spirometry findings consistent with obstructive lung disease (OR

Table 1. Characteristics of the study population and comparison by level of education. ${ }^{a}$

\begin{tabular}{|c|c|c|c|c|}
\hline \multirow[t]{3}{*}{ Characteristic } & \multirow{3}{*}{$\begin{array}{c}\text { Sample as a } \\
\text { whole } \\
(n=358)\end{array}$} & \multicolumn{2}{|c|}{ Years of schooling } & \multirow[t]{3}{*}{ p* } \\
\hline & & $\geq 10$ & $<10$ & \\
\hline & & $(n=126)$ & $(n=232)$ & \\
\hline Female gender & $227(63)$ & $85(68)$ & $142(61)$ & 0.19 \\
\hline Age, years & $49[19-63]$ & $43[33-55]$ & $56[15-66]$ & 0.01 \\
\hline Monthly family income per household member, $\mathrm{R} \$$ & $\begin{array}{c}1,066 \\
{[683-1,666]}\end{array}$ & $\begin{array}{c}1,312 \\
{[843-1,895]}\end{array}$ & $\begin{array}{c}950 \\
{[625-1,565]}\end{array}$ & $<0.01$ \\
\hline Years of schooling & $7[4-11]$ & $12[11-14]$ & $4[3-7]$ & $<0.01$ \\
\hline Body mass index, $\mathrm{kg} / \mathrm{m}^{2}$ & $27[23-32]$ & 27 [24-32] & $26[22-31]$ & 0.02 \\
\hline Presence of comorbidities ${ }^{\mathrm{b}}$ & $154(43)$ & $42(34)$ & $112(48)$ & $<0.01$ \\
\hline History of exposure to rural areas & $193(54)$ & $46(37)$ & $147(63)$ & $<0.01$ \\
\hline Physical activity $>2$ h/week & $62(17)$ & $22(18)$ & $40(17)$ & 0.92 \\
\hline Former smoker & $53(15)$ & $16(13)$ & $37(16)$ & 0.43 \\
\hline Rhinitis & $258(72)$ & $97(78)$ & $161(69)$ & 0.09 \\
\hline Flu vaccination in the last year & $241(67)$ & $69(56)$ & $172(74)$ & $<0.01$ \\
\hline Use of moderate/high doses of inhaled medication ${ }^{c}$ & $198(55)$ & $59(47)$ & $139(60)$ & 0.03 \\
\hline Previously intubated for asthma & $14(4)$ & $5(4)$ & $9(4)$ & 0.58 \\
\hline Adequate environmental control & $263(74)$ & $96(77)$ & $167(72)$ & 0.30 \\
\hline \multicolumn{5}{|l|}{ Device used for the administration of inhaled corticosteroids } \\
\hline Spray & $97(27)$ & $42(34)$ & $55(24)$ & 0.11 \\
\hline Capsule-based dry powder inhaler & $225(63)$ & $73(58)$ & $152(65)$ & \\
\hline None & $36(10)$ & $10(8)$ & $26(11)$ & \\
\hline Patients receiving inhaled corticosteroids for free ${ }^{d}$ & $228(71)$ & $81(70)$ & $147(71)$ & 0.91 \\
\hline Incorrect use of the inhaler ${ }^{d}$ & $34(10)$ & $16(14)$ & $18(9)$ & 0.15 \\
\hline ACQ-6 Score > 1.5 & $113(32)$ & $39(30)$ & $74(32)$ & 0.73 \\
\hline Good treatment adherence ${ }^{d}$ & $272(85)$ & $92(80)$ & $180(88)$ & 0.06 \\
\hline Post-bronchodilator FVC, \% of predicted value & $99[87-110]$ & 98 [88-107] & $100[86-112]$ & 0.65 \\
\hline Post-bronchodilator $\mathrm{FEV}_{1}$, \% of predicted value & $91[75-105]$ & 92 [77-104] & $90[74-106]$ & 0.67 \\
\hline Spirometry findings consistent with obstructive lung disease & $68(19)$ & $21(17)$ & $47(20)$ & 0.48 \\
\hline
\end{tabular}

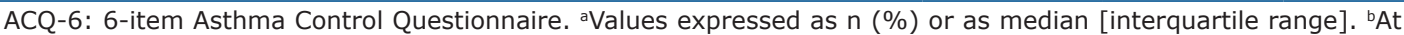
least one of the following: diabetes, systemic arterial hypertension, depression, and heart disease. ${ }^{c} A t$ least 800 $\mu \mathrm{g} / \mathrm{day}$ of budesonide or equivalent + long-acting $\beta_{2}$ agonist. ${ }^{\mathrm{d}}$ Considering only the 322 patients using inhaled corticosteroids. * $\geq 10$ vs. $<10$ years of schooling. Chi-square test for dichotomous variables; the Mann-Whitney test for ordinal and continuous variables. 
Table 2. Binary logistic regression analysis of the association between the number of years of schooling and indicators of asthma severity.

\begin{tabular}{|c|c|c|}
\hline Variables & Unadjusted OR (95\% CI) & Adjusted OR* (95\% CI) \\
\hline ACQ-6 score > 1.5 & $1.02(0.97-1.07)$ & $0.99(0.94-1.05)$ \\
\hline Obstructive lung disease & $0.96(0.90-1.02)$ & $1.00(0.99-1.01)$ \\
\hline Uncontrolled asthma ${ }^{\mathrm{a}}$ & $0.97(0.90-1.04)$ & $1.03(0.95-1.10)$ \\
\hline Use of moderate/high doses of inhaled medication ${ }^{c}$ & $0.95(0.90-0.99)$ & $0.99(0.94-1.06)$ \\
\hline
\end{tabular}

ACQ-6: Asthma Control Questionnaire with six questions. ${ }^{a} \mathrm{ACQ}-6>1.5$ and/or obstructive lung disease on spirometry. ${ }^{b}$ At least $800 \mu \mathrm{g} /$ day of budesonide or equivalent + long-acting $\beta_{2}$ agonist.

*Adjusted for age, monthly family income per household member, place of assessment (public or private clinic), and history of rural exposure.

$=1.00 ; 95 \% \mathrm{CI}: 0.99-1.01)$; use of moderate/high doses of inhaled medication (OR $=0.99 ; 95 \% \mathrm{CI}$ : 0.94-1.06); and uncontrolled asthma (OR $=1.03$, 95\% CI: 0.95-1.10).

Figures 1 and 2 show the number of years of schooling, in medians and interquartile ranges (IQRs), in relation to treatment adherence and inhaler technique, respectively. The level of education (number of years of schooling) was similar between the group of patients in whom treatment adherence was good and that of those in whom it was poor-7 years (IQR: 4-11) vs. 8 years (IQR: 4-12, $p=0.08$ )-as well as between the group of patients who made errors in the use of their inhaler and that of those who did not -8 years (IQR: 4-12) vs. 7 years (IQR: 4-11, $p=0.41$ ).

\section{DISCUSSION}

Our results suggest that a low level of education is not a risk factor for uncontrolled asthma. In our sample, patients had access to pulmonologists and to treatment. Previous studies have shown that individuals in situations of social vulnerability (with a low level of education and a low income) are at greater risk of uncontrolled asthma. ${ }^{(2-4,12)}$ However, in those studies, ${ }^{(2-4,12)}$ the patients had no guaranteed access to a physician or to treatment. Our study adds new information to the literature, indicating that it is possible to control asthma in individuals with a low level of education if access to a specialist physician and to treatment is facilitated. In recent years, several initiatives have been implemented with the aim of expanding patient access to asthma treatment. The results have been promising, at the local level. ${ }^{(5,7)}$ Nevertheless, because the proportion of individuals with uncontrolled asthma is still quite high in the general population, ${ }^{(8)}$ these initiatives need to be further expanded.

The literature indicates that patients with fewer years of schooling have more difficulty adhering to therapy and making proper use of inhalers. ${ }^{(1)}$ Our study did not produce similar results. The good levels of treatment adherence currently seen in Brazil are probably due to easier access to medication, which is dispensed for free. ${ }^{(5,7)}$ The high rate of patients who use inhalers correctly can probably be attributed to increased physician awareness of the need to train patients in their use. In addition, there are new devices that are simpler to use and, therefore, less subject to errors. Most of the patients in our study sample were

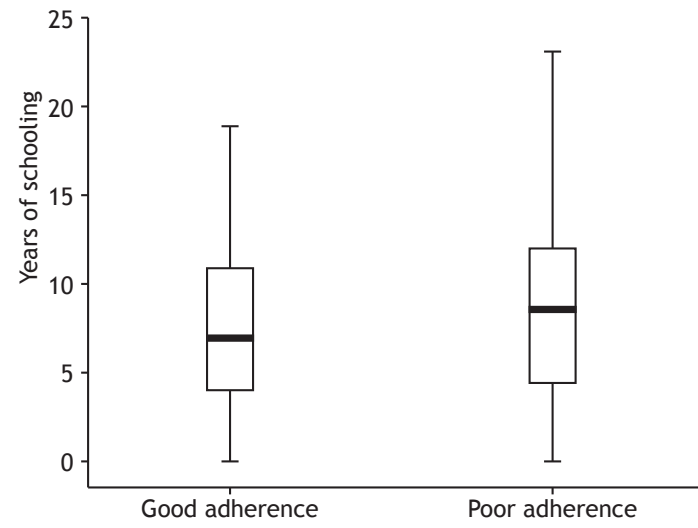

Figure 1. Number of years of schooling, by level of treatment adherence. $\mathrm{p}=0.08$ between the two groups.

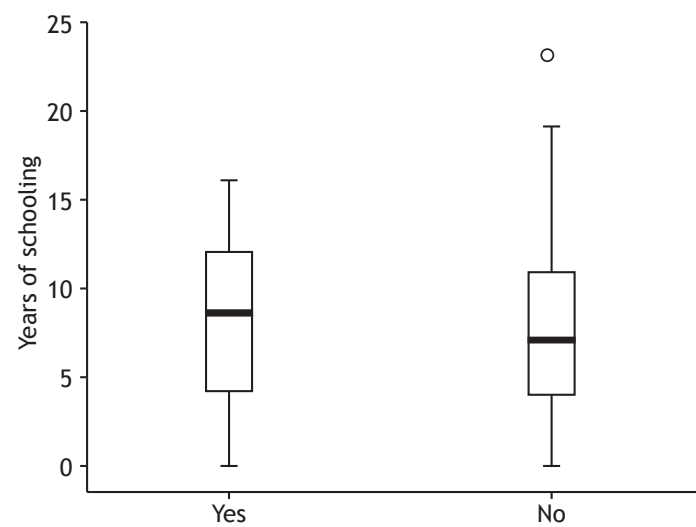

Figure 2. Number of years of schooling, by quality of inhaler technique. $p=0.41$ between the two groups.

using capsule-based dry powder inhalers, which are easier to use. These factors probably contributed to the fact that the level of education was not found to be a limiting factor for asthma control.

One limitation of the present study was the fact that our patients were being followed by a specialist physician (a pulmonologist). Therefore, the results cannot be generalized to patients who are being followed by general practitioners. Another potential limitation is that, in our sample, patients with a lower level of education had more often been exposed to rural environments, which could potentially modify asthma. ${ }^{(13-15)}$ We attempted to minimize this confounder by adjusting the binary logistic regression analysis for 
a history of such exposure. Age is another factor that modifies the severity of asthma. ${ }^{(16,17)}$ In our sample, the patients with a lower level of education were older than were those with a higher level of education. Therefore, the analyses that assessed the relationship between level of education and asthma control were adjusted for patient age. Our study also has several strengths, including the fact that we evaluated patients seen at public and private clinics, as well as patients in various age groups. That increases the external validity of our results. Another noteworthy aspect is that we used validated instruments to quantify asthma control and treatment adherence.
In conclusion, a low level of education does not appear to be a risk factor for inadequate asthma control in a population of patients with access to specialist physicians and to treatment. In addition, patient level of education is apparently not a limiting factor for adequate treatment adherence or proper inhaler technique. Therefore, a low level of education does not seem to be the cause of the high morbidity of asthma in populations in situations of social or economic vulnerability. It is likely that asthma control in these populations depends mainly on facilitating access to medical specialists and to treatment.

\section{REFERENCES}

1. O'Conor R, Wolf MS, Smith SG, Martynenko M, Vicencio DP, Sano $M$, et al. Health literacy, cognitive function, proper use, and adherence to inhaled asthma controller medications among older adults with asthma. Chest. 2015;147(5):1307-1315. https://doi. org/10.1378/chest.14-0914

2. Apter AJ, Wan F, Reisine S, Bender B, Rand C, Bogen DK, et al. The association of health literacy with adherence and outcomes in moderate-severe asthma. J Allergy Clin Immunol. 2013;132(2):321-7. https://doi.org/10.1016/j.jaci.2013.02.014

3. Ellison-Loschmann L, Sunyer J, Plana E, Pearce N, Zock JP, Jarvis D, et al. Socioeconomic status, asthma and chronic bronchitis in a large community-based study. Eur Respir J. 2007;29(5):897-905. https:// doi.org/10.1183/09031936.00101606

4. Hafkamp-de Groen E1, Sonnenschein-van der Voort AM, Mackenbach JP, Duijts L, Jaddoe WW, Moll HA, et al. Socioeconomic and sociodemographic factors associated with asthma related outcomes in early childhood: the Generation R Study. PLoS One. 2013;8(11):e78266. https://doi.org/10.1371/journal.pone.0078266

5. Brandão HV, Cruz CM, Santos Ida S Jr, Ponte EV, Guimarães A, Augusto Filho A. Hospitalizations for asthma: impact of a program for the control of asthma and Allergic rhinitis in Feira de Santana. J Bras Pneumol. 2009;35(8):723-9. https://doi.org/10.1590/S180637132009000800002

6. Stelmach R, Cerci Neto AC, Fonseca AC, Ponte EV, Alves G, Araujo-Costa IN, et al. A workshop on asthma management programs and centers in Brazil: reviewing and explaining concepts. J Bras Pneumol. 2015;41(1):3-15. https://doi.org/10.1590/S180637132015000100002

7. Cruz AA, Souza-Machado A, Franco R, Souza-Machado C, Ponte EV, Moura Santos $P$, et al. The impact of a program for the control of asthma in a low-income setting. World Allergy Organ J. 2010;3(4):167-74. https://doi.org/10.1097/NOX.0b013e3181dc3383

8. Marchioro J, Gazzotti MR, Nascimento OA, Montealegre F, Fish J, Jardim JR. Level of asthma control and its relationship with medication use in asthma patients in Brazil. J Bras Pneumol. 2014;40(5):487-94. https://doi.org/10.1590/S1806-37132014000500004

9. Leite M, Ponte EV, Petroni J, D’Oliveira Júnior A, Pizzichini E,
Cruz AA. Evaluation of the asthma control questionnaire validated for use in Brazil. J Bras Pneumol. 2008;34(10):756-63. https://doi. org/10.1590/S1806-37132008001000002

10. Morisky DE, Green LW, Levine DM. Concurrent and predictive validity of a self-reported measure of medication adherence. Med Care. 1986;24(1):67-74. https://doi.org/10.1097/00005650198601000-00007

11. Cerveri I, Corsico AG, Accordini S, Niniano R, Ansaldo E, Antó JM, et al. Underestimation of airflow obstruction among young adults using FEV1/FVC $<70 \%$ as a fixed cut-off: a longitudinal evaluation of clinical and functional outcomes. Thorax. 2008;63(12):1040-5. https://doi. org/10.1136/thx.2008.095554

12. Antunes FP, Costa Mda C, Paim JS, Vieira-da-Silva LM, Cruz AA Natividade M, et al. Social inequalities in spatial distribution of hospital admissions due to respiratory diseases [Article in Portuguese]. Cad Saude Publica. 2013;29(7):1346-56. https://doi.org/10.1590/S0102$311 \times 2013000700009$

13. Ponte EV, Rasella D, Souza-Machado C, Stelmach R, Barreto ML, Cruz AA. Reduced asthma morbidity in endemic areas for helminth infections: a longitudinal ecological study in Brazil. J Asthma 2014;51(10):1022-7. https://doi.org/10.3109/02770903.2014.936454

14. Ponte EV, Cruz AA, Athanazio R, Carvalho-Pinto R, Fernandes FL, Barreto $\mathrm{ML}$, et al. Urbanization is associated with increased asthma morbidity and mortality in Brazil. Clin Respir J. 2018;12(2):410-417. https://doi.org/10.1111/crj.12530

15. Cruz AA, Stelmach R, Ponte EV. Asthma prevalence and severity in low-resource communities. Curr Opin Allergy Clin Immunol. 2017;17(3):188-193. https://doi.org/10.1097/ACl.0000000000000360

16. Ponte EV, Lima A, Almeida PCA, de Jesus JPV, Lima VB, Schilone $\mathrm{N}$, et al. Age is associated with asthma phenotypes. Respirology 2017;22(8):1558-1563. https://doi.org/10.1111/resp.13102

17. Ponte EV, Stelmach R, Franco R, Souza-Machado C, SouzaMachado A, Cruz AA. Age is not associated with hospital admission or uncontrolled symptoms of asthma if proper treatment is offered. Int Arch Allergy Immunol. 2014;165(1):61-7. https://doi org/10.1159/000367924 